\title{
Práticas de Gerenciamento de Impressões em empresas de capital aberto do setor elétrico brasileiro*
}

\author{
Prácticas de gestión de impresiones en empresas que cotizan en bolsa en el sector eléctrico brasileño \\ Impression Management Practices in Publicly Listed Companies in the Brazilian Electricity Sector
}

Jefferson Pereira de Andrade

Universidade Federal da Paraiba, Brasil

DOI: https://doi.org/10.11144/Javeriana.cc21.pgie

pereira_jp2008@hotmail.com

ORCID: http://orcid.org/0000-0001-8967-8827

Recepção: 02/04/2019

Wenner Glaucio Lopes Lucena

Aprovação: 04/11/2019

Universidade Federal da Paraiba, Brasil

Publicação: 05/06/2020

ORCID: http://orcid.org/0000-0002-2476-7383

\section{Resumo:}

O presente estudo tem como objetivo verificar a influência do resultado contábil no uso de técnicas de gerenciamento de impressão nos relatórios da administração de empresas brasileiras do subsetor de energia elétrica. Para isso foram investigadas 18 empresas de capital aberto entre 2012 e 2016, utilizando-se Análise de Regressão Simples e da Análise Fatorial Confirmatória. Os resultados demonstraram indícios de manipulação visual, uma vez que as empresas aumentam o número de elementos visuais, em períodos de baixo desempenho financeiro. Também foi possível perceber uma maior frequência de palavras positivas em períodos de baixo desempenho, o que sugere que as empresas do setor energia elétrica utilizam-se de técnicas de gerenciamento de impressões no conteúdo de seus relatórios, por meio de alterações na redação texto de modo influenciar a decisão dos investidores que se baseiam nesse relatório.

Códigos JEL: G41, M41

Palavras-chaves: efeito framing, gerenciamento de impressões, resultados contábeis.

\section{Resumen:}

El presente estudio tiene como objetivo verificar la influencia del resultado contable en el uso de técnicas de gestión de impresión en los informes de la administración de las empresas brasileñas en el subsector de la electricidad. Para esto, se investigaron 18 empresas que cotizan en bolsa entre 2012 y 2016, utilizando análisis de regresión simple y análisis factorial confirmatorio. Los resultados mostraron signos de manipulación visual, ya que las empresas aumentan el número de elementos visuales, en períodos de bajo rendimiento financiero. También fue posible notar una mayor frecuencia de palabras positivas en períodos de bajo rendimiento, lo que sugiere que las empresas del sector eléctrico utilizan técnicas para gestionar las impresiones en el contenido de sus informes, a través de cambios en la redacción del texto influir en la decisión de los inversores en función de ese informe.

Códigos JEL: G41, M41

Palabras clave: efecto de framing, gestión de impresiones, resultados contables.

\section{Abstract:}

The present study aims to verify the influence of the accounting result in the use of printing management techniques in the reports of the administration of Brazilian companies in the electricity sub-sector. For this, 18 publicly traded companies were investigated between 2012 and 2016, using Simple Regression Analysis and Confirmatory Factor Analysis. The results showed signs of visual manipulation, since companies increase the number of visual elements, in periods of low financial performance. It was also possible to perceive a greater frequency of positive words in periods of low performance, which suggests that companies in the electricity sector use impression management techniques in the content of their reports, through changes in the text writing so influence the decision of investors based on that report.

JEL Codes: G41, M41

Keywords: Framing effect, impression management, accounting results.

\section{Autor notes}

\footnotetext{
a Autor para correspondência. Correio eletrônico: pereira_jp2008@hotmail.com
} 


\section{Introdução}

A dinâmica organizacional vivida pelas empresas de capital aberto exige da sua administração a transparência de suas decisões e desempenho. Essa transparência é alcançada principalmente por meio da divulgação voluntária ou obrigatória de relatórios que versão sobre diversos aspectos empresariais.

No que tange a desempenho, as demonstrações contábeis correspondem a um dos principais relatórios divulgados pelas empresas, atuando como redutores da assimetria informacional existente entre gestores e investidores.

As demonstrações contábeis são caracterizadas por sua estrutura rígida, técnica e objetiva, que desconsidera a divergência de conhecimento entre os investidores. Como consequência, nos últimos anos, o relatório de administração tem ganhado bastante atenção por se tratar de uma alternativa a divulgação do desempenho empresarial, principalmente por se tratar de um relatório de linguagem menos técnica e narrativa (Rocha \& Procianoy, 2004; Silva, Rodrigues \& Abreu, 2007).

O fato da objetividade das demonstrações contábeis desconsiderando as preferências e sofisticação dos investidores promove distintas percepções quanto à mesma informação. De acordo com Verrecchia (2001) das diferentes percepções dos investidores originam-se preferências quanto às informações reportadas, sendo elas explicadas por Thomas (1991) como resultado de diferentes processos cognitivos em nível de individual.

Ao estudar as percepçóes humanas em ambiente de risco, Tversky e Kahneman (1986) demonstraram que do processo decisório origina-se o efeito framing responsável por moldar a percepção dos usuários em relação às informações reportadas. Com base no efeito framing, e que muitos dos gestores têm utilizados de prática de gerenciamento de impressóes para estabelecer uma imagem positiva do desempenho empresarial (Hooghiemstra, 2000; Merkl-Davies, Brennan \& Mcleay, 2011; Oliveira, Kilimnik \& Fornaciari, 2012).

O gerenciamento de impressões corresponde a um campo de estudo da psicologia social destinado a entender como os indivíduos se apresentam a outros para ser percebido como favorável ou positivo (Hooghiemstra, 2000). O gerenciamento de impressões passou a ser adotado nas organizações como uma resposta aos desafios da legitimidade (O’Keefe \& Conway, 2008). Os investidores exigem das empresas resultados cada vez maiores, o que as estimulam a adotarem essas ferramentas, principalmente nas narrativas que discorrem sobre os desempenhos financeiro e ambiental (Clatworthy \& Jones, 2006; Brennan \& MerklDavies, 2013).

O uso de técnicas de gerenciamento de impressões é empregado principalmente em relatórios cujas narrativas não são regulamentadas ou auditadas, como as declarações do presidente, cartas para os acionistas e análise financeiras e operacionais, discussão e análise de gestão pública, prospectos de ofertas públicas iniciais, entre outros (Brennan \& Merkl-Davies, 2013).

Entre este rol de relatórios favoráveis ao gerenciamento de impressões encontra-se o relatório de administração, que embora existam direcionamentos para o seu conteúdo, conforme descritos na Lei 6.404/76, na Lei 11.638/10 e na orientação normativa no 15 da Comissão de Valores Imobiliários (1980), ele não apresenta uma estrutura rígida como as demonstrações contábeis. O que permite sua utilização como objeto de legitimação e gerenciamento de impressões conforme apontado por Tostes e Vasarhelyi (2010) e Teixeira, Silva, de Oliveira Durso \& da Cunha (2017).

Dada as possibilidades de utilização do relatório da administração como objeto de gerenciamento de impressões, o presente trabalho objetivou verificar a influência do desempenho do exercício na utilização de práticas de gerenciamento de resultados nos relatórios da administração de empresas brasileiras de capital aberto do subsetor de energia elétrica.

O estudo de empresas brasileiras de capital aberto se justifica em função do crescimento verificado no mercado financeiro dos anos, inclusive com o aumento da participação de investidores individuais, os quais segundo a B3 -Brasil, Bolsa Balcão- em agosto de 2019 passou a representar 17,54\% dos investidores totais, 
além disso, o desempenho do setor de energia elétrica foi impactado pela Lei 12.875/13 que estabeleceu o sistema de bandeiras tarifárias.

Apesar do gerenciamento de impressões ter sido objeto de investigação em trabalhos como Silva et al. (2007), Rodrigues (2012), Teixeira et al. (2017) e Vargas Almeida e Júnior (2014), não foi possível identificar pesquisas que relacionaram ogerenciamento de impressão com o desempenho do período. Assim, nesta lacuna encontrada na literatura é que se insere a presente pesquisa.

\section{O efeito framing e gerenciamento de impressóes}

É por meio da racionalidade que os indivíduos são capazes de tratar as informações de maneira objetiva, sem tendências, propensões e aversões, entretanto os aspectos cognitivos dificultam esse tratamento objetivo intervindo nas decisões tomadas (Barreto, Macedo \& Alves, 2013). A tomada de decisão em ambientes de incerteza é afetada positivamente pela capacidade dos indivíduos agirem racionalmente.

De outra forma, a Teoria do Prospecto, destaca que os desvios de racionalidade foram demonstrados pelos autores Kahneman e Tversky (1979) a medida que ficou evidente a relação entre os aspectos cognitivos e as decisões financeiras em ambiente de risco, o que promoveria desvios de racionalidade. Segundo Cardoso, Riccio e Lopes (2008) a ideia principal na Teoria do Prospecto é que em ambientes de incerteza a tomada de decisão corresponde a uma escolha entre percepção e risco, indicado por Tversky e Kahneman (1986) como resultado de um processo decisório de duas fases: estruturação e avaliação.

$\mathrm{Na}$ fase de estruturação as percepções são moldadas a partir da maneira como o problema ou as informações são apresentadas, bem como, pelas regras, hábitos e expectativas do decisor. Nesta fase, segundo Tversky e Kahneman (1986) origina-se o efeito framing, que possui relação direta como os resultados pretendidos e cuja escolha será totalmente afetada pela manipulação da forma de apresentação das informações.

A partir da utilização do efeito framing, Mayer e Avila (2010) demonstram que é possível que se intervenha na decisão dos indivíduos sem que haja uma distorção da informação ou que se ocultem determinados dados, apenas promovendo mudanças sutis na sua estruturação. Uma das maneiras de se promover essa manipulação de informações é denominada gerenciamento de impressões -GI-.

O gerenciamento de impressões é resultado de dois elementos básicos: $\mathrm{O}$ objeto a ser manipulado -no presente artigo os relatórios da administração-e o objetivo que motiva a manipulação - no presente trabalho o desempenho do período-. Segundo Oliveira, Azevedo \& Borges (2016) a motivação é influenciada por três fatores principais:

- O valor atribuído às metas desejadas: $O$ quão importante e reportar bons resultados para a organização,

- A relevância do objetivo das impressões: O significado de resultados positivos para os investidores, e

- A discrepância entre a imagem atual do indivíduo e a imagem que ele deseja transmitir: comparação do resultado obtido com o desejado.

Para Oliveira et al. (2012) as marcas são construídas pelas empresas informando aos stakeholders e a sociedade a imagem a qual querem ser associadas, o que confere ao gerenciamento de impressões a conotação de uma tentativa de controle dos feedbacks por parte dos gestores (Merkl-Davies, Brennan \& Mcleay, 2011).

Por meio da manipulação dos relatórios anuais, as empresas conseguem moldar proativamente as percepções dos acionistas e stakeholders sobre os resultados e eventos organizacionais, além disso, é possível utilizar-se do gerenciamento de impressões de forma retroativa, como nas prestações de contas (Merkl-Davies et al., 2011). 
De acordo com Aerts (2005) nas prestações de contas é comum que as empresas utilizem de aspectos defensivos e de auto atribuição (tendência de atribuir resultados positivos as próprias ações, e resultados negativos a eventos externos) tornando-se assim um mecanismo de percepções retroativo.

É possível utiliza-se de prática de gerenciamento de impressão tanto para a fixação de uma imagem positiva como negativa (Mohamed \& Gardner, 2004). Regularmente verifica-se a existência de tais práticas nos relatórios corporativos como uma tentativa da fixação de uma imagem positiva, principalmente no que tange o desempenho financeiro e o desempenho ambiental de uma empresa (Brennan \& Merkl-Davies, 2013). Em períodos de desempenho ruim é mais provável que as empresas se utilizem do gerenciamento de impressões em seus relatórios (Clatworthy \& Jones, 2006).

De acordo com Clatworthy e Jones (2006) uma das principais questões envolvendo a gestão de impressões em relatórios financeiros, consistem nos potenciais conflitos com a exigência de apresentar desempenho financeiro anual de maneira neutra e imparcial como exigidos em relatórios contábeis. Relatórios corporativos cujo conteúdo não é regulamentado ou auditado constituem um universo mais propício para o desenvolvimento dessas práticas, como por exemplo, declarações do presidente, cartas para os acionistas, análise financeira e operacional, discussão e análise de gestão pública e prospectos de ofertas públicas iniciais (Brennan \& Merkl-Davies, 2013). Ainda segundo os autores, o desempenho corporativo comunicado a partir das narrativas estão mais sujeitas a essa manipulação.

As demonstrações contábeis representam uma estrutura rígida com pouco espaço para manipulação e gerenciamento de impressão, não seguem o perfil indicado por Brennan \& Merkl-Davies (2013) como propenso a tais práticas, além de reguladas pelas normas internacionais de contabilidade, pela legislação societária e pelas normas provenientes de órgãos reguladores, as demonstraçóes contábeis estão sujeitas a auditoria independentes.

O relatório da administração empregado no Brasil, por outro lado, apresenta características que o torna um potencial instrumento de gerenciamento de impressões. Trata-se de um documento não padronizado e discricionário permitindo que os autores se utilizem de termos, figuras e gráficos como forma de benefício próprio (Vargas et al., 2014). Além disso, o Relatório da Administração contém comentários sobre o desempenho empresarial, não existe uma regulamentação rígida quanto ao seu conteúdo, além de não está sujeito a auditoria independente.

De acordo com Oliveira et al. (2016) a literatura sobre a qualidade dos relatórios financeiros demonstra que as estratégias podem assumir a forma de mensagens verbais/não verbais ou subliminares para manipular o conteúdo e apresentação de informações financeiras, sendo as principais práticas listadas a seguir.

- Manipulação da legitimidade: Envolvem técnicas de escrita que confunde e distraí os leitores, ofuscando más notícias;

- Manipulação retórica: Para ofuscar as más notícias os gerentes utilizam-se da persuasão para constantemente distorcer o discurso narrativo;

- Manipulação temática: Para esconder más notícias os gerentes enfatizam boas notícias e fazem uso de palavras positivas e otimistas;

- Manipulação visual e estrutural: Para esconder as más notícias os gerentes utilizam-se da ênfase visual, da repetição, reforço de ideias, ordenação e localização estratégica de informações para criar ruídos e enfatiza ideias;

- Comparação de desempenho: Para enfatizar boas notícias os gestores utilizam-se da seletividade dos números para gerar um valor de referência para o desempenho;

- Escolha de números referentes a ganhos: os gerentes enfatizam boas notícias evidenciando alguns números e ocultado outros;

- Atribuições de desempenho: Os gerentes atribuem bons resultados aos fatores internos e maus resultados aos fatores externos. 
A partir dessas práticas os gestores são capazes de atenuar a percepção dos usuários quando ao desempenho organizacional, embora Oliveira et al. (2016) citem oito ferramentas de gerenciamento alvo de pesquisadores como Beattie e Jones (1997, 2002, 2012); O’keefe e Conway (2008); Lima (2012); Brennan e MerklDavies (2013); Vargas et al. (2014); Teixeira et al. (2017) o presente estudo se limita a manipulação retórica, manipulação temática e a manipulação visual e estrutural.

\section{Desenvolvimento das hipóteses}

A ideia de manipulação por meio da retórica implica na tentativa do gestor convencer o usuário da informação por meio de sua narrativa, o que para Newman, Pennebaker, Berry \& Richards (2003) pode dizer muito de suas intenções. As palavras podem ensinar muito sobre o que as pessoas pensam, sobre suas emoções e motivações, e os vários estilos linguísticos e classes gramaticais utilizadas podem revelar traços comportamentais e emocionais dos autores.

No que tange o processo decisório, de acordo com Barreto et al. (2013) um grande número de informações (consequentemente de palavras) promove a dispersão do conteúdo e o isolamento de detalhes que poderiam contribuir para o processo decisório.

Ao relatar o desempenho corporativo, o resultado contábil positivo por si só é sinônimo de competência gerencial, e não demanda explicações adicionais para torná-lo consistente com a imagem corporativa desejada, mas o resultado negativo demanda informações adicionais para torná-lo legítimo e inteligível (Scott \& Lyman, 1968). Neste contexto se desenvolve a primeira hipótese de pesquisa.

Hipótese 1: O lucro contábil afeta negativamente o tamanho do relatório de administração das empresas.

Além do tamanho do relatório, as palavras utilizadas também apresentam relevância no contexto do gerenciamento de resultados. As alterações no discurso podem incluir palavras que promovam situações como insinuação, promoção organizacional, exemplificação, intimidação, suplicação, retratação, desculpa e restituição (Mendonça \& Andrade, 2003).

Aerts (1994), por exemplo, descobriu que em períodos de baixo desempenho as empresas reduzem o uso da palavra técnicas em seus relatórios, dissociado o resultado negativo de sua imagem. Clatworthy e Jones (2006) verificaram uma tendência de perspectiva futura nas cartas do presidente quanto o desempenho financeiro é ruim. Já Vargas et al. (2014) contataram a diminuição dos termos que expressam o resultado e aumento de outros indicadores de desempenho em períodos de resultado contábil desfavorável.

Patelli e Pedrini (2013) ao analisarem as narrativas financeiras anuais descobriram uma relação entre o tom otimista das cartas do presidente com o resultado contábil da empresa, indicando sinais da manipulação temática nesses relatórios. No Brasil, Silva et al. (2006) descobriram que metade dos relatórios de administração são otimistas, já Silva et al. (2007) concluíram que os relatórios pessimistas fazem referências aos fatores externos, sugerindo a existência de algum tipo de gerenciamento de impressões. Diante dessas evidências, foi desenvolvida a segunda hipótese de pesquisa.

Hipótese 2: O periodo de prejuizo afeta positivamente o número de palavras otimistas no relatório de administração das empresas.

Segundo Beattie e Jones (1999) o uso de gráficos e tabelas também corresponde a uma ferramenta utilizada para o gerenciamento de impressões pelos gestores. A utilização de gráficos torna as informações mais claras e chamam mais a atenção dos usuários, além disso, eles são mais prováveis de serem lembrados devido a maior capacidade humana de lembrar padrões visuais em relação aos números e textos (Beattie \& Jones, 2012).

Características como proporções, fundos chamativos, cores, destaques em séries temporais e outros artifícios podem ser utilizados como ferramenta de gerenciamento de impressóes. Nos relatórios anuais os gráficos correspondem a uma importante ferramenta de comunicação de dados contábeis, entretanto, esses podem ser facilmente manipulados para os próprios interesses (Beattie \& Jones, 2002). 
De acordo com Beattie e Jones $(1999,2012)$ existem três causas principais de distorções em gráficos: A seletividade (Diz respeito desde a decisão de usar ou não gráficos, até seletividade dos dados usados, das variáveis contábeis disponíveis), a construção gráfica (uso de técnicas de distorcem as informações transmitidas como a alteração de forma e mudanças nos eixos do gráfico), e a escolha do design gráfico. Embora essas causas possam ser utilizados de maneira conjunta, elas são independentes.

Em geral, os gráficos são usados seletivamente para projetar uma visão mais favorável do desempenho financeiro esperado. Além disso, há evidências de que os gráficos distorcem materialmente os dados de desempenho financeiro subjacentes a favor das empresas (Clatworthy $\&$ Jones, 2006).

A distorção por seletividade corresponde as mais básicas, entretanto, pode ter implicações importantes no contexto do processo decisório do usuário da informação, dessa forma, é proposta a terceira hipótese de pesquisa.

Hipótese 3: O resultado contábil afeta negativamente o número de elementos visuais no relatório de administração das empresas.

Assim como os gráficos as tabelas correspondem a elementos visuais que podem mudar a percepção dos leitores quanto ao conteúdo apresentado, embora nem todo tipo de manipulação aplicada aos gráficos se aplique a elas, ainda sim estão sujeitas a seletividade e mudança de design, tornando importante o seu estudo como elemento visual.

\section{Metodologia de pesquisa}

\section{População e amostra}

A população pesquisada corresponde a 60 empresas do subsetor de energia elétrica, listadas na Brasil, Bolsa, Balcão e que desempenham as funções de geração, transmissão e distribuição de energia elétrica.

A escolha da população se deu em função de relevância econômica e social do setor. Segundo dados do Instituto Brasileiro de Geografia e Estatística (2016) essas empresas fornecem energia para aproximadamente 67,8 milhões de residências no país, o que corresponde a aproximadamente $99,7 \%$ total de residências.

No mercado financeiro, as empresas do setor elétrico correspondem a aproximadamente $20 \%$ das empresas não financeiras listadas na Brasil, Bolsa, Balcão, sendo esse um setor bastante expressivo. Porém, segundo Matos e Matos (2014) como consequência a Lei 12.875/2013 essas empresas passaram a ser percebida pelos investidores como mais arriscada devido o controle exercido pelo órgão regulador, a Agência Nacional de Energia Elétrica -ANEEL-.

A Lei 12.875/13 estabeleceu o sistema de bandeiras tarifárias para o valor da energia elétrica praticado no mercado, o que a nível de empresa, impacta o desempenho reportado nos demonstrativos financeiros, e em nível macro, como demonstrado por Brambilla e Mueller (2004) afeta o Produto Interno Bruto -PIBdo país. Dessa forma, as empresas listadas neste setor são propícias ao gerenciamento de impressões com o objetivo reduzir a percepção de risco dos investidores.

Para o alcance do objetivo pretendido, o presente estudo utilizou-se de duas técnicas de análise das evidências, a saber, Análise Fatorial Confirmatória -AFC- e a Análise de Regressão. A utilização de diferentes técnicas implicou na necessidade de duas amostras de pesquisa, ambas definidas em função dos critérios de alternância do resultado contábil apurado (utilizado para permitir a comparação das alterações nos relatórios da administração frente ao resultado apresentado); da disponibilidade dos dados (demonstração do resultado do exercício e relatório da administração).

A amostra 1 utilizada para relacionar o tamanho do relatório da administração (hipótese 1) e a utilização de elementos visuais (hipótese 3) ao resultado contábil, compreende empresas que apresentaram alternância do resultado contábil no período compreendido de 2012 a 2016. Dentre as 60 empresas listadas no subsetor 
de energia, 22 não apresentaram alternância de resultados conforme critério pré-estabelecido e 20 não apresentaram dados para todos os anos da análise, resultando assim em uma amostra final de 18 empresas e 90 relatórios, representando aproximadamente $30 \%$ do universo pesquisado.

A mostra 2 utilizada na AFC além dos pré-requisito anteriormente definidos, considerou ainda a limitação de processamento dos dados do software Iramuteq ${ }^{\circ}$ que recomenda que o corpus textual não ultrapasse 20 relatórios, exigindo assim um critério de afunilamento da amostra. A amostra 2 compreende as empresas que apresentaram alternância de resultado nos anos de 2015 e 2016, o que resultou em 9 empresas e 18 relatórios.

\section{Procedimentos metodológicos}

A análise se restringiu aos comentários da administração no tange o desempenho econômico-financeiro contido nos relatórios de administração e ocorreu em duas etapas. A primeira delas destinada a avaliar as hipóteses de pesquisa 1 e 3, foi desenvolvida a partir da correlação de Pearson e um modelo de regressão simples estimada pelo método dos mínimos quadrados ordinários -OLS- descrita nas equações 1 e 2:

$$
R A_{i t}=\beta_{1}+\beta_{2} * D E S_{i t}+\varepsilon
$$

$$
R A_{i t}=\beta_{1}+\beta_{2} \star D E S_{i t}+A N O+\varepsilon
$$

Onde,

$\mathrm{RA}_{\mathrm{it}}=$ Características do relatório de administração da empresa i no tempo t;

$\beta_{1}=$ intercepto da equação;

$\mathrm{DES}_{\text {it }}=$ desempenho da empresa i no tempo t;

ANO = efeitos fixos (controle dos dados em painel);

$\varepsilon=$ resíduos da regressão.

As características do relatório de administração analisadas foram: o tamanho e o uso de elementos visuais. No que tange o tamanho do relatório, baseado nos estudos de Newman et al. (2003), Silva et al. (2007); Rodrigues (2012) e Vargas et al. (2014) utilizou-se como proxy o número de palavras usadas para discorrer sobre o desempenho. Já em relação à utilização de elementos visuais, foram utilizadas como proxies o número de quadros/tabelas e o número de gráficos contidos ao longo do texto do relatório, assim como utilizado por Vargas et al. (2014) e Rodrigues (2012), respectivamente. O desempenho da empresa foi mensurado pelo lucro líquido do período apurado em dezembro de cada ano.

Os efeitos fixos da equação 2 objetiva controlar os efeitos da tendência natural observada por Rodrigues (2012) no tamanho dos relatórios de administração, ao longo do tempo. Além disso, a equação de regressão resultante constitui um teste de sensibilidade dos resultados.

A segunda fase da análise, destinada à avaliação da hipótese de pesquisa número 2 ocorreu por meio da análise fatorial confirmatória -AFC-. A AFC foi calculada utilizando-se palavras com frequência mínimas de 10 nos relatórios de administração. A partir da AFC é possível associar textos a variáveis, ou seja, permite avaliar os textos a partir das perspectivas de variáveis de categorização, como o resultado do período (Iramuteq, 2016). Desta forma a técnica permite a comparação da frequência de palavras em relação ao resultado contábil.

As palavras identificadas como mais frequentes foram categorizadas como otimistas e pessimistas, além de serem avaliadas a partir das perspectivas ou dimensões do gerenciamento de impressões de Mendonça 
e Andrade (2003), que são estratégias diretas e assertivas, e táticas diretas defensivas conforme descritas na tabela 1.

TABELA 1

Dimensões do gerenciamento de impressões

\begin{tabular}{|l|l|}
\hline \multicolumn{1}{|c|}{ Estratégias diretas e assertivas } & \multicolumn{1}{|c|}{ Táticas diretas defensivas } \\
\hline $\begin{array}{l}\text { Insinuação: ocorre quando se usa do GI } \\
\text { como uma ferramenta para tornar a } \\
\text { empresa mais atrativa. }\end{array}$ & $\begin{array}{l}\text { Explicação: explicações de um evento nas } \\
\text { quais se buscam minimizar a severidade } \\
\text { aparente de uma situação dificil. }\end{array}$ \\
\hline $\begin{array}{l}\text { Promoção organizacional: busca } \\
\text { apresentar a empresa como uma } \\
\text { organização altamente competente e bem- } \\
\text { sucedida. }\end{array}$ & $\begin{array}{l}\text { Retratação: explicações antes de } \\
\text { acontecimentos que podem refletir } \\
\text { negativamente na imagem da organização. }\end{array}$ \\
\hline $\begin{array}{l}\text { Exemplificação: usado para protegera } \\
\text { imagem integra da empresa. }\end{array}$ & $\begin{array}{l}\text { Handicapping Organizacional: refere-se } \\
\text { ao esforço realizado pela organização para } \\
\text { fazer sucesso em tarefas aparentemente } \\
\text { impossiveis. }\end{array}$ \\
\hline $\begin{array}{l}\text { Intimidação: prega a entidade como uma } \\
\text { entidadepoderosa a qual se mostra capaz } \\
\text { de infligir sofrimento sobre os que } \\
\text { frustram seus esforçose objetivos. }\end{array}$ & $\begin{array}{l}\text { Desculpa: admissão da culpa por um } \\
\text { evento negativo. }\end{array}$ \\
\hline $\begin{array}{l}\text { Suplicação: projetam uma imagem de } \\
\text { dependência ve vulnerabilidade da } \\
\text { organização. }\end{array}$ & $\begin{array}{l}\text { Restituição: oferta de compensação os } \\
\text { quais são estendidas pela organização ao } \\
\text { ofendido. }\end{array}$ \\
\hline
\end{tabular}

Fonte: Mendonça e Andrade (2003).

Cada palavra resultante da AFC foi analisada com base em sua utilização dentro dos relatórios buscando identificar o grau de proximidade com as dimensões ilustradas no quadro 01.

\section{Análise dos dados}

Inicialmente para alcance do objetivo proposto a tabela 2 apresenta a estatística descritiva das variáveis utilizadas neste estudo para caracterizar o tamanho dos relatórios da administração e o uso de recursos visuais (número de palavras, número de tabelas e o número de gráficos), além do lucro líquido do período.

TABELA 2

Estatística descritiva dos dados, 90 observações

\begin{tabular}{|l|r|r|r|r|}
\hline \multicolumn{1}{|c|}{ Variável } & \multicolumn{1}{c|}{ Média } & \multicolumn{1}{c|}{ Desvio padrão } & \multicolumn{1}{c|}{ Minimo } & \multicolumn{1}{c|}{ Máximo } \\
\hline Lucro liquido & $-264.302,70$ & 1.919 .377 & -14.441 .607 & 3.425 .899 \\
\hline $\mathrm{N}^{\circ}$ de palavras & $1.196,74$ & 794,08 & 163 & 3.557 \\
\hline $\mathrm{N}^{\circ}$ de tabelas & 4,90 & 4,67 & - & 15 \\
\hline $\mathrm{N}^{\circ}$ de gráficos & 1,35 & 2,22 & - & 9 \\
\hline
\end{tabular}

Fonte: dados da pesquisa.

No que tange o lucro líquido das empresas analisadas a análise descritiva evidencia uma grande amplitude e dispersão, consequência dos critérios previstos na metodologia da pesquisa onde para compor a amostra, as empresas deveriam apresentar lucro e prejuízo no período analisado, resultando em um ponto de mínimo negativo e um ponto de máximo positivo. O maior lucro foi de $\mathrm{R} \$ 3.425 .899,00$ e o maior prejuízo foi de $\mathrm{R}$ \$-14.441.607,00 ambos apresentados pela Eletrobrás nos anos de 2016 e 2015 respectivamente.

Quanto ao número de palavras as empresas apresentaram um número médio de 1200 palavras, com desvio padrão de 794 palavras. O maior número de palavras constante no relatório também é apresentado pela Eletrobrás corresponde a 3.553 palavras no ano de 2016, ainda com relação ao gráfico é possível perceber que a empresa também apresentou o maior número de palavras nos anos de 2012 e no ano de 2014. Como maior empresa, dentre as empresas da análise a Eletrobrás foi a empresa que apresentou o maior relatório da administração, o que é consistente com os achados de Silva et al. (2007) que descobriram uma relação positiva entre o tamanho do relatório e o tamanho da empresa. 
O número médio de tabelas apresentadas nos 90 relatórios analisados é de 4,90 com desvio padrão da média de 4,67. Em sua análise dos relatórios da administração, Rodrigues (2012) constatou que nem todas as empresas apresentam recursos visuais em seus relatórios de administração, no presente estudo isso foi constatado nas empresas AES Elpa, Emae e Omega Energia. O maior número de tabelas é apresentado pela Eletrobrás e apresentam informações como receita, custos, impostos, EBITDA, entre outros assuntos.

Quanto às representações gráficas de informações, a média apresentada foi de 1,35 gráficos por relatório, com desvio padrão de 2,22. O menor número de gráfico foi apresentado pelas mesmas empresas que não apresentavam tabelas em seus relatórios (AES Elpa, Emae e Omega Energia), acrescidas das empresas Ampla, CEEE-GT, Celesc, Celpa e Cesp. Esses dados sugerem que essas empresas não se utilizam do mecanismo de seletividade descrito por Beattie e Jones $(1999,2012)$ como ferramenta de gerenciamento de impressóes.

Visando detectar associações entre as variáveis lucro e o número de palavras, número de gráficos e número de tabelas foi efetuado o teste de correlação de Pearson. Os testes indicaram que os dados não seguiam a distribuição normal, entretanto, conforme apontado por Brooks (2014) pelo teorema do limite central o pressuposto pode ser relaxado.

TABELA 3

Correlação de Pearson

\begin{tabular}{|l|r|r|r|}
\hline & $\mathrm{N}^{\circ}$ de palavras & \multicolumn{1}{|c|}{$\mathrm{N}^{\circ}$ de tabelas } & \multicolumn{1}{|c|}{$\mathrm{N}^{\circ}$ de gráficos } \\
\hline Lucro liquido & $-0,2213$ & $-0,1325$ & $-0,3032$ \\
\hline & $0,0371^{* *}$ & 0,2159 & $0,0039^{* * *}$ \\
\hline & ${ }^{* * *}$ Significativo a 1\%, \\
& ${ }^{* *}$ Significativo a 5\%. \\
Fonte: dados da pesquisa.
\end{tabular}

A tabela 3 mostra os resultados da correlação para as variáveis lucro e número de palavras do relatório foram significativos e negativos, fornecendo indícios que o número de palavras contidas no relatório de administração diminui à medida que lucro apurado aumenta, corroborando da ideia defendida por Scott e Lyman (1968) de que resultados negativos demandam maior explicação. Embora significativa, a correlação apresentada entre as duas variáveis é fraca conforme apontado por Figueiredo Filho e Silva Júnior (2009).

O coeficiente de correlação de Pearson não foi significativo para as variáveis número de tabelas e lucro líquido, já o número de gráficos com significância de $1 \%$ apresentou uma relação negativa com o lucro líquido do período, sugerindo que os relatórios de administração das empresas que apresentaram lucro no período possuem um menor número de gráficos do que os relatórios das empresas que apresentaram prejuízos, corroborando assim com Beattie e Jones (2002) e sugerindo traços de manipulação gráfica.

Os coeficientes significativos e positivos que estabelecem uma relação entre número de palavras com o número de tabelas e o número de gráficos são apontadas por Rodrigues (2012) e por Silva et al. (2007) como um indício de que as empresas que apresentam os maiores relatórios, apresentam também o maior uso de recursos visuais.

Para avaliar as hipóteses de pesquisa 1 e 3 a tabela 4 demonstra o resultado da análise de regressão simples, entre as variáveis estudadas. 
TABELA 4

Análise da manipulação retórica e visual

\begin{tabular}{|c|c|c|c|c|c|c|}
\hline \multirow{3}{*}{\begin{tabular}{|l|} 
Painel A \\
Variáveis \\
Independentes
\end{tabular}} & \multicolumn{6}{|c|}{ Variáveis dependentes } \\
\hline & \multicolumn{2}{|c|}{$N^{\circ}$ de palavras } & \multicolumn{2}{|c|}{$\mathrm{N}^{\circ}$ de tabelas } & \multicolumn{2}{|c|}{$N^{*}$ de gráficos } \\
\hline & (I) & (II) & (III) & (IV) & (V) & (VI) \\
\hline \multirow[t]{2}{*}{ Constante } & $1172543^{\prime \prime}$ & 1272009 "* & $4813712^{2 *}$ & 5.718 .916 & $12558^{\prime \prime}$ & 1389599"* \\
\hline & [107259] & [2070455] & {$[0.6495137]$} & {$[1308158]^{-\prime}$} & {$[0.2272896]$} & {$[0.6874278]$} \\
\hline \multirow[t]{2}{*}{ Lucro } & $-0.0000916^{\prime \prime}$ & $-0.0000918^{*}$ & $-3.22 \mathrm{e}-07^{* \prime}$ & $-3.61 \mathrm{e}-07^{\prime \prime}$ & $-3.50 \mathrm{e}-07^{\cdots}$ & $-3.75 \mathrm{e}-07^{*}$ \\
\hline & {$[0.0000353]$} & {$[0.0000361]$} & {$[1.60 \mathrm{e}-07]$} & {$[1.62 \mathrm{e}-07]$} & {$[1.18 \mathrm{e}-07]$} & {$[1.73 \mathrm{e}-07]$} \\
\hline Efeito fixo & - & Ano & - & Ano & - & Ano \\
\hline Painel B & (I) & (II) & & & (I) & (II) \\
\hline $\mathrm{R}^{2}$ & 0.0490 & 0,0087 & & VIF (média) & 1 & 1,5 \\
\hline Teste $\mathrm{F}$ & $0.0111^{*}$ & $0.0097 \cdots$ & & White & $12.83^{\cdots-}$ & $37,24{ }^{\prime \prime}$ \\
\hline Jarque-Bera & $18.71^{\cdots-\cdot}$ & $15^{\cdots-}$ & & \begin{tabular}{|l|}
$\begin{array}{l}\text { Wooldridge } \\
(1,17)\end{array}$ \\
\end{tabular} & $0.053^{\prime \prime}$ & $6,347^{*}$ \\
\hline Painel C & (III) & (IV) & & & (III) & (IV) \\
\hline $\mathrm{R}^{2}$ & 0.0175 & 0.0090 & & VIF (média) & 1 & 1,5 \\
\hline Teste $\mathrm{F}$ & $4.06^{\prime \prime}$ & 1.23 & & White & $6.30^{\circ-}$ & $10.78^{\prime \prime}$ \\
\hline Jarque-Bera & $11.52^{\cdots *}$ & 10.9 " & & Wooldridge & $13315^{\cdots \cdots}$ & 31415 "' \\
\hline Painel D & (V) & (VI) & & & (V) & (VI) \\
\hline $\mathrm{R}^{2}$ & 0.0919 & 0.1098 & & \begin{tabular}{|l|} 
VIF (média) \\
\end{tabular} & 1 & 1,5 \\
\hline Teste $\mathbf{F}$ & $4.71^{\prime \prime}$ & 1.67 & & White & $9.00^{\prime \prime}$ & $40.02^{\cdots \cdots}$ \\
\hline Jarque-Bera & $110.4^{\cdots \cdots}$ & $103.4^{\cdots "}$ & & Wooldridge & $19463^{\cdots}$ & $23027{ }^{\prime \prime \prime}$ \\
\hline
\end{tabular}

Nota 1. Devido aos problemas de homocedasticidade e autocorrelação os valores acima são resultado da correção de Newey West. Nota 2. Os valores do erro padrão estão indicados abaixo do coeficiente entre colchetes.

Fonte: dados da pesquisa.

A regressão I presente no painel A é resultado da regressão OLS tendo como variável dependente o número de palavras. O coeficiente da variável lucro demonstrou ser negativo e significativo, sugerindo que o aumento no número de palavra é em parte explicado pelo resultado aferido pela entidade.

$\mathrm{Na}$ regressão II também disponível no painel A o controle do painel por meio dos efeitos fixos dos anos implicaram na permanência do resultado da primeira regressão, entretanto o coeficiente de determinação de ambas as regressões se demonstraram próximo a zero o que segundo Gujarati e Porter (2011) significam que não há relações entre o regressando e o repressor, implicando na rejeição da hipótese de pesquisa 1, que afirma que existe uma relação negativa entre o tamanho do relatório da administração e o resultado contábil, contrastando com os resultados achados de Vargas et al. (2014). Em seu estudo os autores encontraram uma maior média de palavras em períodos de resultado positivo. Já Silva et al. (2007) ao analisarem o exercício financeiro de 2002, verificaram que o tamanho dos relatórios da administração aumenta a medida que o lucro diminui.

As regressões III e IV apresentam como variável dependente o número de tabelas presentes nos Relatórios de Administração. Na regressão III embora o teste F tenha demonstrado significância e o coeficiente da variável lucro tenha sido significativo e negativo, o coeficiente de determinação também foram próximos de zero. Já modelo IV quando o painel foi controlado pelos efeitos dos anos a capacidade preditiva do modelo foi nula, corroborando com os Vargas et al. (2014) não encontraram evidências de que em períodos de baixo desempenho as empresas utilizam-se de maior número de tabela.

As duas últimas colunas do painel A demonstram os resultados das regressões para a variável dependente número de gráficos, os resultados sugerem uma relação entre o resultado contábil líquido e o número de gráficos presentes nos relatórios de administração das companhias analisadas. Diferentemente das regressões anteriores o coeficiente de correlação apresentado não foi próximo de zero, e o coeficiente significativo e negativo indicam uma relação positiva entre o resultado e o uso da técnica de seletividade gráfica indicada por Clatworthy e Jones (2006). Esse resultado difere do resultado encontrado por Vargas et al. (2014) que não encontraram diferenças estatística entre o número de gráficos utilizadas por empresas brasileiras que apresentaram prejuízo no ano de 2009 e lucro em 2010. 
Posteriormente, a correlação e a análise de regressão efetuadas utilizou-se da técnica de Análise Fatorial Confirmatória com base na Lei Hipergeométrica para analisar a frequência de uso das palavras. A tabela 5 demonstra algumas das palavras de maior frequência nos relatórios analisados.

\section{TABELA 5}

Análise Fatorial Confirmatória dos relatórios da administração

\begin{tabular}{|c|c|c|c|c|c|}
\hline Termo apresentado & Lacro & Prejuizo & Termo apresentado & Lucro & Prejuizo \\
\hline resultado financeiro & 0,4528 & $-0,4528$ & valor & $-0,7225$ & 0,7225 \\
\hline segmento & $-0,4422$ & 0,4422 & acionista & 0,3274 & $-0,3274$ \\
\hline negativo & 0,3333 & $-0,3333$ & indicador & 0,2651 & $-0,2651$ \\
\hline tarifa & $-1,0625$ & 1,0625 & demonstracoes_financeiras & 0,2491 & $-0,2491$ \\
\hline custo & 0,642 & $-0,642$ & eletrobras & 0,519 & $-0,519$ \\
\hline abaixo & $\begin{array}{ll}-0,9584 \\
\end{array}$ & 0,9584 & pagamento & 0,2231 & $-0,2231$ \\
\hline decrescimo & 0,3871 & $-0,3871$ & eletronorte & 1,1067 & $-1,1067$ \\
\hline crescer & $-0,5845$ & 0,5845 & ebitda_ajustado & 0,3871 & $-0,3871$ \\
\hline participacoes_societarias & 0,1947 & $-0,1947$ & custo_de_construcao & 0,2324 & $-0,2324$ \\
\hline receber & 1,7122 & $-1,7122$ & passivo_a descoberto & $-0,2762$ & 0,2762 \\
\hline despesa_liquida & $-0,4422$ & 0,4422 & tributo & $-0,3402$ & 0,3402 \\
\hline ativo & 0,4528 & $-0,4528$ & elevado & $-0,2499$ & 0,2499 \\
\hline reversao & 0,675 & $-0,675$ & impacto & 4,7002 & $-4,7002$ \\
\hline alcancaram & $-0,5523$ & 0,5523 & receita_de_construcao & 0,3591 & $-0,3591$ \\
\hline encargo & $-0,3054$ & 0,3054 & atualizacao & 1,056 & $-1,056$ \\
\hline provisoes_operacionais & $-0,2499$ & 0,2499 & apurado & 0,2651 & $-0,2651$ \\
\hline recurso & 0,5478 & $-0,5478$ & receita & 0,7122 & $-0,7122$ \\
\hline passivo & $-0,5523$ & 0,5523 & repasse & $-0,2601$ & 0,2601 \\
\hline reajuste_tarifario & $-0,8973$ & 0,8973 & despesas_operacionais & $-0,3054$ & 0,3054 \\
\hline despesa & 2,0481 & $-2,0481$ & venda_de_energia & $-0,5845$ & 0,5845 \\
\hline decorrente & 0,6383 & $-0,6383$ & lucro_liquido & 3,0133 & $-3,0133$ \\
\hline curto prazo & $-0,5523$ & 0,5523 & comparar & $-0,5023$ & 0,5023 \\
\hline instrucao_evm_n & $-0,2499$ & 0,2499 & anterior & $-1,0634$ & 1,0634 \\
\hline mercado & $-0,3077$ & 0,3077 & financeiro & $-0,36$ & 0,36 \\
\hline menor & $-0,8323$ & 0,8323 & ebitda & 0,4901 & $-0,4901$ \\
\hline provisao & 2,2057 & $-2,2057$ & endividamento & $-0,3826$ & 0,3826 \\
\hline acrescimo & $-2,3347$ & 2,3347 & prejuizo_liquido & $-0,5992$ & 0,5992 \\
\hline positivo & 2,5278 & $-2,5278$ & preco & 0,3871 & $-0,3871$ \\
\hline reflexo & $-0,3961$ & 0,3961 & superior & 0,5282 & $-0,5282$ \\
\hline perda & $-1,0648$ & 1,0648 & celg gt & 0,6862 & $-0,6862$ \\
\hline crédito & 0,3591 & $-0,3591$ & efeito & $-0,7843$ & 0,7843 \\
\hline investimento & $-1,5209$ & 1,5209 & mercado_cativo & $-2,9849$ & 2,9849 \\
\hline aumentar & 1,7122 & $-1,7122$ & prejuizo & $-0,7665$ & 0,7665 \\
\hline receita_operacional_liquida & 1,0447 & $-1,0447$ & resultado & 1,9949 & $-1,9949$ \\
\hline operacao & $-0,5523$ & 0,5523 & receita_liquida & $-0,5523$ & 0,5523 \\
\hline crescimento & 0,5591 & $-0,5591$ & receita_bruta & 0,3213 & $-0,3213$ \\
\hline terceiros & $-0,2292$ & 0,2292 & remuneracao & 1,0751 & $-1,0751$ \\
\hline
\end{tabular}

Fonte: dados da pesquisa.

Conforme demonstrado na tabela 5, o resultado contábil é expresso nos relatórios da administração sobre os termos "resultado", "lucro líquido", "prejuízo líquido", "EBITDA” e "EBITDA ajustado”. De acordo como o resultado do teste hipergeométrico, não existe um indício de que as empresas desviem o foco do resultado apresentados por meio da omissão de palavras. Os relatórios em ano de prejuízo apresentam uma maior frequência na utilização do termo prejuízo, além disso verifica-se uma menor frequência do termo genérico "resultado" nestes relatórios, demonstrando uma consistência das narrativas contábeis com os relatórios anuais conforme destacado por Pagliarussi, Guimarães e Ferreira (2015), e semelhante ao encontrado por Merkl-David, Brennan e Mcleay (2011) em empresas do Reino Unido.

Também ficou evidente que diferentemente do resultado apontado por Vargas et al. (2014) não é possível concluir que outros indicadores desempenho, como o EBITDA seja mais utilizado em relatórios que apresentaram prejuízo no período.

Por se tratar de um ramo específico e regulado da economia é de esperar que reflexos da regulamentação sejam encontrados nos relatórios da administração. Palavras como "reajuste tarifário" e "provisões operacionais" são exemplos desses reflexos, entretanto essas palavras são utilizadas com maior frequência nos relatórios em anos de prejuízo e como mecanismo de explicação em frases como: "as provisões operacionais foram influenciadas principalmente pela provisão para contingência"; "as provisões operacionais foram influenciadas principalmente pelos impairment" e "queda no volume de energia vendida no 4 trimestre de 2016 influenciada pelo reajuste tarifário”. Segundo Mendonça e Andrade (2003) o uso de explicações em relatórios corresponde de um evento busca minimizar o efeito de resultados negativos sobre a imagem corporativa. 
Palavras como "curto prazo", "investimento" apresentam uma perspectiva futura otimista em relação ao futuro organizacional. A palavra "curto prazo" mais utilizada em relatórios em períodos de baixo desempenho é utilizado para reforçar os fatos ocorridos em um período curto de tempo, enquanto que a investimento fornece uma perspectiva de crescimento organizacional como observado em frases como: "o ano de 2015 cujo desafio era a retomada de confiança entre governo e empresários para assim destravar investimento visando crescimento"; "os investimentos líquidos realizados pela ampla atingiram R $\$ 889$ milhões em 2016". Tanto as palavras "investimento" como "curto prazo" expressam a tendência das empresas em referir ao futuro de forma otimista, frisando que resultados negativos são passageiros (Clatworthy \& Jones, 2006).

Embora a análise tenha revelado que o termo investimento seja mais frequentemente utilizada em relatórios em períodos de menor desempenho, Silva et al. (2007) afirmam que relatórios otimistas tende a se referir mais sobre os investimentos em função das variações de caixa.

O termo "crescimento" presente com maior intensidade em relatórios em ano de bom resultado, ele figura em alguns momentos como positivo ("investimentos visando o crescimento econômico se mostrou pífio"), hora figura como um tom negativo ("as contas de pessoal, material e serviços apresentaram respectivamente crescimento") o que não permite inferir sobre sua utilização nos relatórios como um indutor de positividade nos textos.

Também é possível observar que o nome das empresas são apresentados com maior frequência nos relatórios onde são reportados bons resultados financeiros, o que segundo Newman et al. (2003) e Thomas (1991) indica uma tentativa de associação ou dissociação da responsabilidade da administração com o resultado apurado, isso é, ao ampliar a frequência com que essas palavras aparecem no texto, a administração induz o leitor a assimilar o resultado como uma competência da gestão empresarial, enquanto que quando se reduz a frequência com que o nome da empresa aparece no texto, o leitor tende a dissociar o resultado do período com a competência da gestão.

Embora os resultados demonstrem indícios de atribuição de explicação, otimismo e dissociação nos relatórios da administração, não possível confirmar a hipótese de pesquisa 3 de que empresas que apresentam prejuízo contábil utilizam-se de maior número de palavras positivas.

\section{Considerações finais}

O presente trabalho teve como objetivo verificar a utilização de ferramentas de gerenciamento de impressão nos relatórios da administração de empresas brasileiras de capital aberto do setor de energia elétrica, considerando períodos de desempenho positivo (lucro) e negativo (prejuízo).

O desempenho, como uma das principais informações prestadas aos investidores, corresponde a uma espécie de termômetro que demonstra a qualidade das decisões da administração. No setor elétrico caracterizado principalmente pela utilização de hidroelétricas, o desempenho é sensível a uma série de fatores que inclui o volume pluvial e mais recentemente o sistema de bandeiras tarifárias responsável por ampliar a percepção de risco dos investidores e consequentemente fornecendo as empresas os dois elementos básicos para a gerenciamento de impressões, o objeto e o objetivo.

Embora muitas técnicas de manipulação possam ser empregadas em relatórios discricionários, a manipulação retórica, temática e visual são suítes e podem passar despercebido por gestores mais desatentos ou menos sofisticados em termos de conhecimento e habilidades. Elas representam uma ameaça ao processo decisório dos investidores e podem conduzir a erros graves.

Embora as três formas de gerenciamento tenham sido testadas, apenas uma delas foi sujeito de confirmação sendo ela a manipulação visual e estrutural. Foram observadas características inerentes a seletividade de informações gráficas, onde a medida que o desempenho aumenta, a quantidade de elementos gráficos aumenta, promovendo destaque de informações e desvio de atenção. 
A pesquisa tem limitação o número de relatórios utilizados na análise fatorial confirmatória, uma vez que o software utilizado limita a utilização dos relatórios impedindo uma maior abrangência da pesquisa.

\section{Referências}

Aerts, W. (1994). On the use of accounting logic as an explanatory category in narrative accounting disclosures. Accounting, organizations and society, 19(4-5), 337-353. https://doi.org/10.1016/0361-3682(94) .

Aerts, W. (2005). Picking up the pieces: impression management in the retrospective attributional framing of accounting outcomes. Accounting, organizations and society, 30(6), 493-517. https://doi.org/10.1016/j.aos.200 4.07.001.

Barreto, P. S., Macedo, M. Á., \& Alves, F. J.S. (2013). Tomada de decisão e teoria dos prospectos em ambiente contábil: uma análise com foco no efeito framing. Revista de Gestão, Finanças e Contabilidade, 3(2), 61-79. https://doi. org/10.18028/rgfc.v3i2.293.

Beattie, V., \& Jones, J. M. (1999). Australian financial graphs: An empirical study. Abacus, 35(1), 46-76. https://doi .org/10.1111/1467-6281.00034

Beattie, V., \& Jones, M. J. (1992). The use and abuse of graphs in annual reports: theoretical framework and empirical study. Accounting and business research, 22(88), 291-303. https://doi.org/10.1080/00014788.1992.9729446

Beattie, V., \& Jones, M. J. (1997). A comparative study of the use of financial graphs in the corporate annual reports of major US And UK Companies. Journal of International Financial Management \& Accounting, 8(1), 33-68. https://doi.org/10.1111/1467-646X.00016

Beattie, V., \& Jones, M. J. (2002). Measurement distortion of graphs in corporate reports: an experimental study. Accounting, Auditing \& Accountability Journal, 15(4), 546-564. https://eprints.gla.ac.uk/772/1/Acc_AudAcc Jo_15\%284\%29546-564.pdf

Brambilla, P. H. M., \& Mueller, B. M. P. (2004). Impacto da energia elétrica no crescimento econômico. Revista de Ciências Jurídicas, 5(1), 33-45. https://doi.org/10.17921/2448-2129.2004v5n1p\%25p

Brennan, N. M., \& Merkl-Davies, D. M. (2013). Accounting narratives and impression management. The Routledge companion to accounting communication (pp. 123-146). London: Routledge Press.

Brooks, C. (2014). Introductory econometrics for finance. Cambridge: Cambridge University Press.

Cardoso, L., Riccio, E. L., \& Lopes, A. B. (2008). O processo decisório em um ambiente de informação contábil: um estudo usando a teoria dos prospectos. Revista de Administração e Contabilidade da UNISINOS, 5(2). https:// doi.org/10.4013/base.20082.01.

Clatworthy, M. A., \& Jones, M. J. (2006). Differential patterns of textual characteristics and company performance in the chairman's statement. Accounting, Auditing \& Accountability Journal, 19(4), 493-511. https://doi.org/10.1 108/09513570610679100.

Comissão De Valores Mobiliários (1980). Instrução Normativa n 015, de 03 de dezembro de 1980. Dispõe sobre as normas e procedimentos para elaboração de demonstrações financeiras consolidadas de companhia aberta e de sociedade de comando de grupo de sociedade que inclua companhia aberta. Brasília, 03 dez. 1980. Disponível em: Recuperado de http://www.cvm.gov.br/legislacao/instrucoes/inst015.html;. Acesso em: 13 dez. 2017.

Figueiredo Filho, D. B., \& Silva Júnior, J. A. D. (2009). Desvendando os Mistérios do Coeficiente de Correlação de Pearson (r). Revista Política Hoje, 18 (1), 115-146. https://doi.org/10.11606/issn.2237-4485.lev.2014.132346.

Gujarati, D. N., \& Porter, D. C. (2011). Econometria Básica. Bookman Editorial.

Hooghiemstra, R. (2000). Corporate communication and impression management- new perspectives why companies engage in corporate social reporting. Journal of Business Ethics, 27(1-2), 55-68. https://doi.org/10.1023/A:10 06400707757.

Instituto Brasileiro de Geografia e Estatística. (2016). Pesquisa Nacional por amostra de domicilio. Recuperado de http s://biblioteca.ibge.gov.br/index.php/biblioteca-catalogo?view=detalhes\&id=298887. 
Iramuteq. (2016). Tutorial para uso do software de análise textual IRAMUTEQ. 2016. . Recuperado de Disponível em: http://www.iramuteq.org/documentation/fichiers/tutoriel-en-portugais;. Acesso em: 01 dez. 2017.

Lima, Diogo Henrique Silva de. (2012). Análise do impacto da divulgação adicional de informações contábeis com o uso de recursos textuais e/ou gráficos sobre a percepção dos indivíduos quanto ao nível de disclosure de uma entidade. Tese de doutorado. Curso de Ciências Contábeis, UNB/UFPB/UFRN, Natal, RN, Brasil.

Matos, R. A., \& Matos, F. V. B. M. (2014). Prêmio de risco regulatório no cálculo do WACC para as revisões tarifárias do setor de energia elétrica: impactos sobre a percepção de risco do mercado à luz da lei 12.783/2013. Revista Espaço Energia, 20(1), 43-63. https://doi.org/10.4025/rimar.v5i1.26616.

Mayer, V. F., \& Avila, M. G. (2010). A influência da estruturação da mensagem em comportamentos relacionados à saúde: um teste experimental. Saúde e Sociedade, 19(3), 685-697. https://doi.org/10.1590/S0104-129020100 00300019 .

Mendonça, C., R., J., \& Andrade, J. A. (2003). Gerenciamento de impressões: em busca de legitimidade organizacional. Revista de administração de empresas, 43(1), 1-13. https://doi.org/10.1590/S0034-75902003000100005.

Merkl-Davies, D. M., Brennan, N. M., \& McLeay, S. J. (2011). Impression management and retrospective sense-making in corporate narratives: A social psychology perspective. Accounting, Auditing \& Accountability Journal, 24(3), 315-344. https://doi.org/10.1108/09513571111124036.

Mohamed, A. A., \& Gardner, W. L. (2004). An exploratory study of interorganizational defamation: An organizational impression management perspective. Organizational Analysis, 12(2), 129-145. https://doi.org/10.1108/eb028 989

Newman, M. L., Pennebaker, J. W., Berry, D. S., \& Richards, J. M. (2003). Lying words: Predicting deception from linguistic styles. Personality and social psychology bulletin, 29(5), 665-675. https://doi.org/10.1177/01461672 03251529.

O'Keefe, P., \& Conway, S. (2008). Impression management and legitimacy in an NGO environment. https://www.rese archgate.net/publication/279503915_Impression_management_and_legitimacy_in_an_NGO_environment

Oliveira, J., Azevedo, G., \& Borges, F. (2016). Impression management and self-presentation dissimulation in Portuguese chairman's statements. Corporate Communications: An International Journal, 21(3), 388-408. DOI: 10.1108/CCIJ-11-2015-0074.

Oliveira, L., Kilimnik, Z., \& Fornaciari, I. (2012). Discurso, ethos e gerenciamento de impressões. Revista Pretexto, 13(4), 11-31. https://doi.org/10.21714/pretexto.v13i4.1383.

Pagliarussi, M., Guimarães, T., \& Ferreira, T. (2015). Harmonia entre as informações contidas no texto e nos números dos relatórios anuais de empresas brasileiras. Revista de Educação e Pesquisa em Contabilidade (REPeC), 9(1). h ttps://doi.org/10.17524/repec.v9i1.1177.

Patelli, L., \& Pedrini, M. (2013). Is the optimism in CEO's letters to shareholders sincere? Impression management versus communicative action during the economic crisis. Journal of Business Ethics, 124(1), 19-34. https://doi. org/10.1007/s10551-013-1855-3.

Rocha, C. F., \& Procianoy, J. L. (2004). Disclosure das companhias abertas brasileiras: um estudo exploratório. Revista Eletrônica de Gestäo Organizacional, 2(3), 1-14. http://www.spell.org.br/documentos/ver/11398/disclosure-d as-companhias-abertas-brasileiras--um-estudo-exploratorio

Rodrigues, F. F. (2012). Fatores determinantes da evolução das informações divulgadas no relatório da administração das empresas brasileiras de capital aberto. Tese de doutarado. Curso de Ciências Contábeis, UNB/ UFPB / UFRN, Brasília, DF, Brasil.

Scott. M. R. \& Lyman. S. M. (1968). Accounts. American Sociological Review, 33(1), 46-62. https://doi.org/10.230 7/2092239.

Silva, C. A., Rodrigues, F. F., \& Abreu, R. L. (2007). Análise dos relatórios de administração das companhias abertas brasileiras: um estudo do exercício social de 2002. Revista de Administração Contemporânea, 11(2), 71-92. http s://doi.org/10.1590/S1415-5552007000200005. 
Silva, C. A., Rodrigues, F. F., Silveira, M. L., \& Silveira, K. J. (2006). Relatórios da administração das companhias brasileiras de capital aberto: uma análise qualitativa. Contextus-Revista Contemporânea de Economia e Gestão, 4(2), 7-16. https://doi.org/10.19094/contextus.v4i2.32075.

Teixeira, D. P., Silva, M. M., de Oliveira Durso, S., \& da Cunha, J. V. A. (2017). A Crise Econômica de 2015 nas Narrativas Contábeis das Empresas Brasileiras: Uma Investigação do Gerenciamento de Impressões nos Relatórios da Administração. Revista Capital Cientifico-Eletrônica (RCC\#)-ISSN 2177-4153, 15(2), 45-61. htt ps://doi.org/10.5935/2177-4153.20170012.

Thomas, A. P. (1991). Towards a contingency theory of corporate financial reporting systems. Accounting, Auditing \& Accountability Journal, 4(4), 40-57. https://doi.org/10.1108/EUM0000000001933.

Tostes, F. P., \& Vasarhelyi, M. A. (2010). A divulgação de informações contábeis e financeiras no mundo virtual. Revista de Contabilidade do Mestrado em Ciências Contábeis da UERJ, 10(2). https://doi.org/10.12979/rcmccuerj.v1 0i2.5595.

Tversky, A., \& Kahneman, D. (1979). Prospect theory: An analysis of decision under risk. Econometrica, 47(2), 263-291. https://www.uzh.ch/cmsssl/suz/dam/jcr:00000000-64a0-5b1c-0000-00003b7ec704/10.05-kahnem an-tversky-79.pdf

Tversky, A., \& Kahneman, D. (1986). Rational choice and the framing of decisions. Journal of Business, 59(4), S251S278. http://www.cog.brown.edu/courses/cg195/pdf_files/fall07/Kahneman\%26Tversky1986.pdf

Vargas, L. H. F., de Almeida, J. E. F., \& Júnior, E. M. (2014). Lucro e prejuízo sob a perspectiva da administração: como os resultados são apresentados nos relatórios de administração? Revista de Educação e Pesquisa em Contabilidade (REPeC), 8(4). https://doi.org/10.17524/repec.v8i4.1119.

Verrecchia, R. E. (2001). Essays on disclosure. Journal of Accounting and Economics, 32(1-3), 97-180. http://dx.doi.o $\mathrm{rg} / 10.1016 /$ S0165-4101(01)00025-8

\section{Notas}

* $\quad$ Artigo de pesquisa científica e tecnológica.

Licencia Creative Commons CC BY 4.0

Para citar este artigo: Andrade, J. P., \& Lucena, W. G. L. (2020). Práticas de gerenciamento de impressões em empresas de capital aberto do setor elétrico brasileiro. Cuadernos de Contabilidad, 21. https://doi.org/10.1 1144/Javeriana.cc21.pgie 